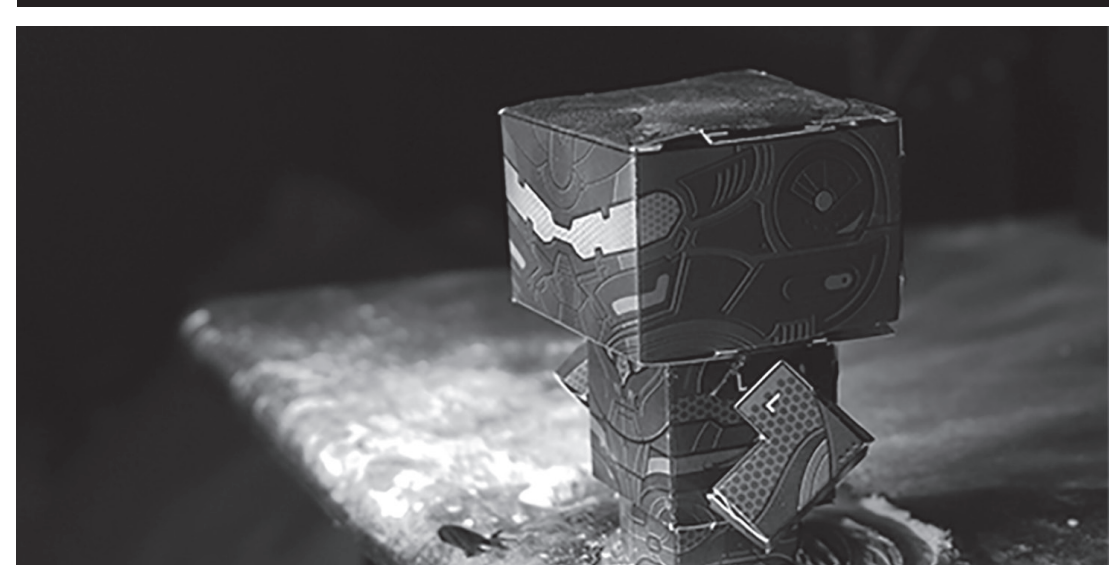

\title{
COMUNICACIÓN Y EXPERIENCIA MEDIADA POR LA REALIDAD VIRTUAL ${ }^{1}$
}

\section{COMMUNICATION AND EXPERIENCE MEDIATED BY VIRTUAL REALITY}

Por

Luis Alfredo Avendaño Rodríguez ${ }^{2}$

Fundación Universitaria Los Libertadores

laavendanor@libertadores.edu.co

\section{Jorge Mario Hernández Perilla}

Fundación Universitaria Los Libertadores

jmhernandezp@libertadores.edu.co 
Resumen: El presente artículo hace parte del proyecto de investigación: La comunicación inmersiva mediada por la realidad virtual a través de video $360^{\circ}$ en la comunicación del patrimonio cultural del centro de Bogotá, de la Fundación Universitaria Los Libertadores. A continuación, se presenta un panorama de las tecnologías de la comunicación audiovisual que actualmente permiten otras formas de "sumergirse" en sus productos y que buscan afectar directamente el sistema nervioso del espectador, a partir de una nueva experiencia de usuario. Este reconocimiento de conceptos se genera con el fin de mostrar cómo este tipo de tecnologías permite a los creadores audiovisuales generar experiencias en cuanto a los factores de percepción y cómo el desarrollo de estas tecnologías afecta a los usuarios del proyecto matriz del que se desprende este artículo.

Palabras clave: realidad virtual, realidad aumentada, inmersión, mímesis, comunicación audiovisual.

Abstract: This article is part of the research project: La comunicación inmersiva mediada por la realidad virtual a través de video $360^{\circ}$ en la comunicación del patrimonio cultural del centro de Bogotá (Immersive communication mediated by virtual reality through $360^{\circ}$ video in the communication of the cultural heritage of the downtown of Bogotá), from Fundación Universitaria Los Libertadores. Hereunder, it is shown an overview of audiovisual communication technologies, which currently allow other forms of "submerging" in their products, and seek to affect directly the nervous system of the viewer, based on a new user experience. This recognition of concepts is generated in order to show how this kind of technologies enable audiovisual creators to generate experiences regarding the perception factors and how the development of these technologies will permit to affect the users of the parent project from which this article is derived.

Keywords: virtual reality, augmented reality, immersion, mimesis, audiovisual communication.
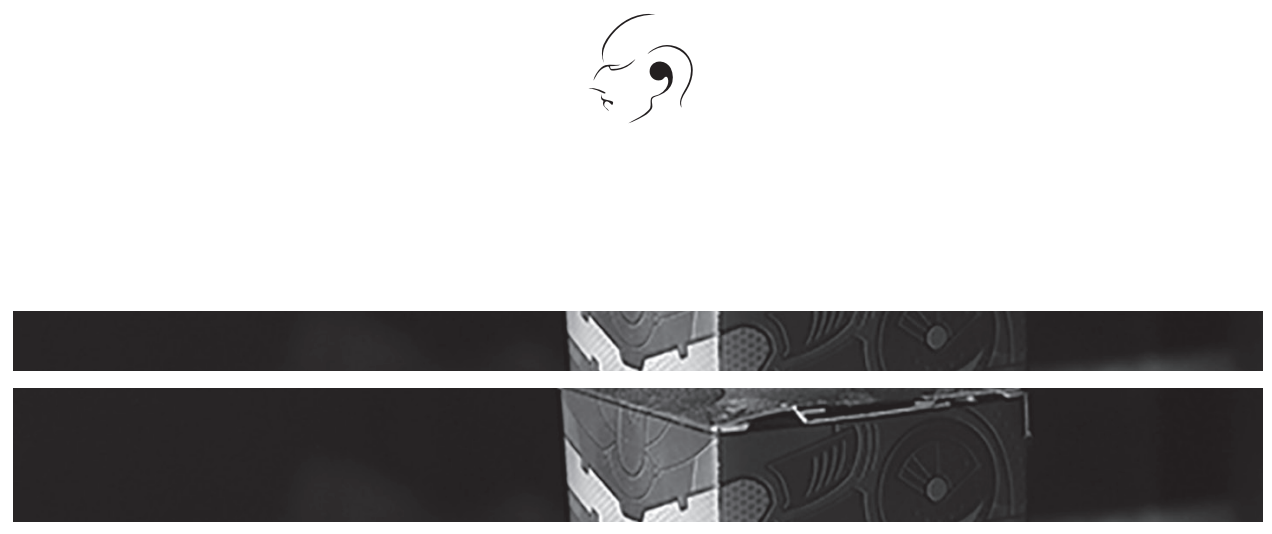


\section{Comunicación y experiencia mediada por la realidad virtual.}

En nuestra sociedad, las imágenes miméticas producidas por mediaciones tecnológicas ${ }^{4}$ juegan un papel determinante. Están presentes en nuestros actos comunicativos, en los sistemas de representación y en la producción de pensamiento en general; también son parte vital de nuestra cotidianidad, de nuestra interacción social, de nuestra manera de construir memoria y expresión. Las imágenes miméticas/mediáticas son utilizadas para construir realidad o realidades del mundo, e incluso son los testigos indexicales de fenómenos que no podemos ver con nuestros propios ojos. Las imágenes brindan conocimiento, comunicación y por consiguiente ayudan a construir sentido y crear relatos que nos permiten interactuar día a día con nuestro alrededor (Donald, 1998).

Hay autores que ven esta particularidad de la sociedad moderna como algo peligroso que está llevando a los colectivos humanos a procesos de aislamiento y ensimismamiento, pues la imagen en muchos casos está reemplazando al objeto real, al punto de desdibujar la línea que define lo ficcional y lo verdadero. La realidad es un concepto mediatizado ahora por la generación de imágenes miméticas que son capaces de reemplazar la experiencia del mundo en el cerebro humano (Donald, 1998). No obstante, más allá de las implicaciones sociales, culturales y sicológicas de este fenómeno actual, debemos primero preguntarnos: ¿Por qué la fotografía, el cine, el vídeo y simuladores de realidad virtual, tienen el poder de ser asimilados por las personas como relatos que se asemejan a nuestra conciencia y tienen la facultad de transmitir emociones, significados y producir sentido en nuestras mentes? Como menciona Cuadrado (2005): "Los Medios de Comunicación audiovisuales son instrumentos que representan la información que quieren transmitir a través del lenguaje audiovisual, y son elementos importantes en el proceso de socialización de las personas" (p. 12).

En consecuencia, primero se debe conocer lo que revelan las imágenes con su eficacia sobre nosotros, sobre nuestras mentes y nuestra manera de percibir y fabricar el mundo como una realidad aceptable para poder sobrevivir en él. Así mismo, las imágenes pueden mostrar cómo el cerebro se comporta a través de un proceso de evolución y construye lo que comúnmente denominamos realidad y su diferencia con lo que consideramos ficción. Las imágenes miméticas no solo involucran la vista y el oído, también tienen la propiedad de transmitir emociones que hacen que el cuerpo entero reaccione por medio de sentimientos y cogniciones; logran de este modo un nivel de inmersión tal que nuestra mente, así sepa que son ficciones, actúa como si estuviera ante situaciones reales (Donald, 1998).

La cognición aquí no es entendida como algo ajeno al cuerpo; por el contrario, para poder entender lo que ocurre en nuestra mente cuando vemos una película, jugamos un videojuego o nos enfrentamos a una experiencia de realidad virtual, tenemos que asimilar el cerebro humano como una "mente encarnada". En otras palabras, nuestra 
generación de conocimiento está fundamentada en la experiencia corporal, así como lo está nuestra capacidad de abstracción y de configuración de lenguajes -tanto verbales y no verbales- por medio de los cuales podemos manifestar cogniciones propias de la especie humana como preguntas, conceptos y sentimientos (Grodal, 2009, p 68).

Las tecnologías han llevado a que la comunicación audiovisual salga de su formato de presentación clásico en el que un espectador pasivo interactuaba a través de una sala de cine compuesta por una pantalla y un sistema sonoro envolvente, o un televisor o un computador, entre otros. Dentro de estas nuevas tecnologías de la comunicación audiovisual se encuentran:

\subsection{Realidad Virtual}

Términos como "multimedia", "cross media”, "transmedia”, "realidad virtual" o "aumentada" ya son usuales cuando hablamos de nuevos formatos. Pronto desembarcará también la tecnología sin pantalla. Esta nueva realidad, por ejemplo, obligará al periodista a "pensar" la información y le exigirá determinados cambios a la hora de elaborar el relato (López Hidalgo, 2016):

Se puede considerar que un sistema de realidad virtual es una base de datos interactivos capaz de crear una simulación que implique a todos los sentidos, generada por un ordenador, explorable, visualizable y manipulable en "tiempo real” bajo la forma de imágenes y sonidos digitales, dando la sensación de presencia en el entorno informático (Levis, 1997, p.12).

En ese orden, para Rheingold (1994) "al tener una inmersión audiovisual hace que la realidad virtual sea una experiencia virtual, es decir que la persona tiene la ilusión de "estar" en el espacio generado o mediado por el ordenador, interactuando con los objetos de ese mundo virtual" (p.271). Siguiendo las anteriores ideas, Levis (1997) pregunta por “... esta técnica que cada día sigue en reconfiguración al punto de pensar que ya no necesariamente los ambientes son virtuales, pues cada día se añaden elementos con el fin de estimular sentidos" (p.6).

Una de las conclusiones que se desprenden de la reflexión anterior se refiere a las definiciones de realidad virtual que son cada vez más numerosas y transversales, dependiendo del área de utilización y su papel mediador. Aukstakalnis, Blatner

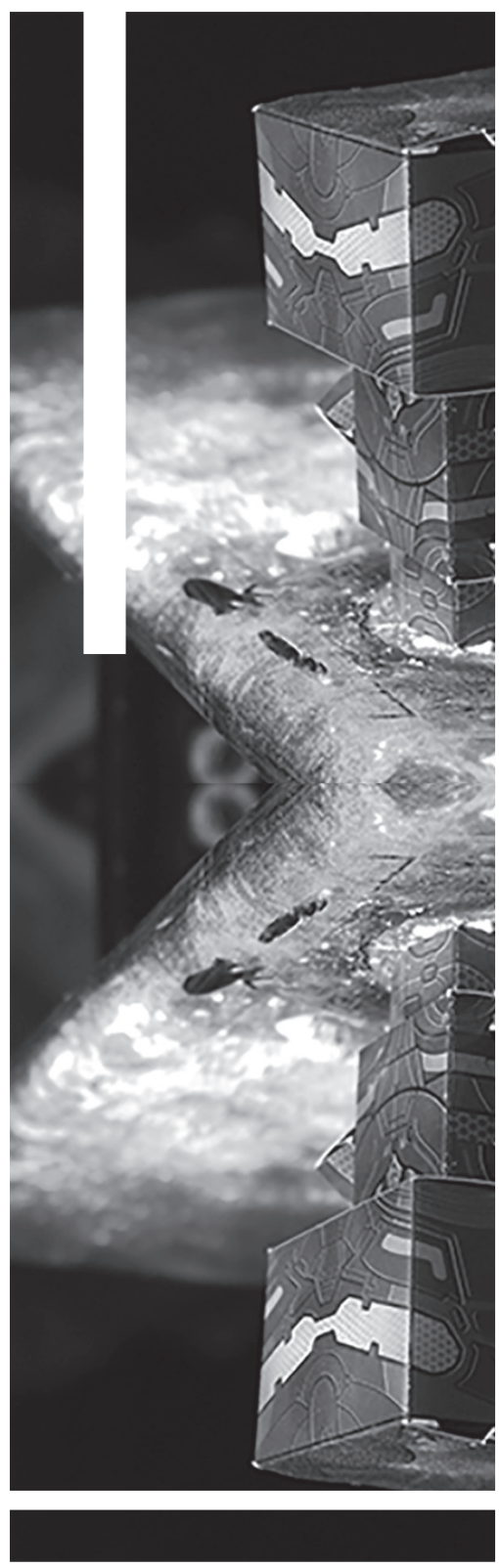


\& Roth (1993) afirman que "la realidad virtual es una forma humana de visualizar, manipular e interactuar con ordenadores y datos complejos" (p.7). Por tanto, la realidad virtual es un sistema de computación usado para crear un mundo artificial en el cual el usuario tiene la impresión de estar en él, por medio de la habilidad de navegar y manipular objetos Manetta y Blade, (2015), y serían realidades virtuales o mejor aún "representaciones integrales". Por ejemplo, se destaca la importancia que tiene la difusión y comunicación del patrimonio cultural y el turismo utilizando la mediación de la realidad virtual. En ese orden, Caro, Luque y Zayas-Fernández (2014) advierte que las "Nuevas Tecnologías de la Información y las Comunicaciones, tanto en la organización como en el desarrollo del viaje, han revolucionado la forma de promocionar un territorio turístico" (p.34).

Además, como ha ocurrido en el periodismo, es un agente importante dentro de las estrategias de comunicación y sobre todo de preservación del patrimonio cultural a través del periodismo inmersivo, que combina la realidad virtual aplicada a narrativas de no ficción y periodismo. Domínguez (2015) afirma: "El Periodismo inmersivo o (...) la realidad virtual y el videojuego influyen en la interfaz e interactividad del relato de actualidad en el profesional de la información” ( p.16).

En líneas generales y sumado a lo anterior, Pérez (2011) afirma: "las instituciones educativas, ministerios de educación y de tecnología, también han considerado e implementado el uso de la realidad virtual inmersiva para ser aplicado en la formación de pedagogías y competencias en los estudiantes" (Pérez, 2011, p.12). En síntesis, la realidad virtual vista desde términos transmediales e hipermediales, pronto estará presente en cada una de las aulas, libros, hogares del mundo; así mismo, evolucionará a una tecnología sin pantalla que pase a ser una pieza importante en procesos de enseñanza, comunicación, logísticos y operativos.

\subsection{Realidad aumentada}

La realidad aumentada $(R A)$ es una variación de los ambientes virtuales o realidad virtual, como se le llama comúnmente. La realidad virtual es una experiencia completamente digital e inmersiva que reemplaza el mundo real por uno simulado; Pérez (2011) afirma que la realidad virtual es "la percepción en 3D de entornos simulados que permiten trasladar al usuario a mundos de ensueño y le posibilitan viajar a través del tiempo al pasado y al futuro" (p.4). Mientras esto sucede, el usuario está inmerso en un ambiente artificial y no puede ver a su alrededor. En contraste, la $R A$ se entiende como "la generación de imágenes nuevas a partir de la combinación de información digital en tiempo real y el campo de visión de una persona” (Johnson, Adams Becker, Gago, García, y Martín, 2013, p.16). Por lo anterior, la $R A$ se puede considerar como una mezcla entre lo completamente artificial y lo completamente real. 
En la definición básica, partiendo de la representación de las capacidades de la $R A$, se enumeran tres características necesarias: según Kipper \& Rampolla, (2012) “debe combinar información real y virtual. Requiere ser interactiva en tiempo real. Debe operar y ser usada en un ambiente en tercera dimensión" (p.4).

La realidad aumentada ha tenido en los últimos años una gran popularidad en los medios publicitarios y la industria editorial, entre otros, debido al uso de teléfonos móviles inteligentes y tabletas que, descargando una aplicación, hacen uso de la cámara interna y de la pantalla del dispositivo para mostrar material 3D: audiovisual que se mezcla con lo que está registrando la cámara del dispositivo en tiempo real, en términos de imágenes en movimiento.

\subsection{Video $360^{\circ}$}

Las cámaras y los videos 360 grados han dejado de ser un producto de la ciencia ficción; muchos de los usuarios de las redes sociales y teléfonos inteligentes, han interactuado alguna vez con alguno. En pocas palabras, se trata de un nuevo punto de vista o narrativa donde el campo de visión y escucha abarca todo el entorno donde la cámara se encuentra posicionada. Son videos grabados en todas las direcciones en un mismo momento; si bien muchos montajes o técnicas de captura sólo relacionan la función de inmersión del video, es importante fijarse también en el valor añadido que presenta el sonido y la capacidad que tiene el sonido biaural o 3D. En este sentido, un buen paisaje o diseño sonoro ayuda mucho a la experiencia de realismo e inmersión del espectador. En la actualidad, en el mercado existen varias opciones de grabación de video que se dividen en dos tipos de técnicas; la primera, es a partir de una cámara $360^{\circ}$ que tiene dos lentes en posiciones opuestas, cada uno de los cuales cubre un ángulo de $240^{\circ}$, de ese modo pueden grabar un punto de vista o plano bastante abierto o amplio. La otra forma es realizar un montaje con varias cámaras, mínimo seis, en un soporte especifico, cada una de las cuales graba en una dirección y ángulo distinto.

Los precios son variados para los diferentes montajes y van desde USD $\$ 200$ hasta USD \$7000. Por otro lado, con el auge de la realidad virtual y los diferentes lanzamientos de productos como cámaras asequibles a bajo costo, softwares de edición e implementos de las diferentes compañías que comercializan el video 360 grados, se ha generado una especie de democratización de la realidad virtual, que ha dado la oportunidad a los usuarios de convertirse en consumidores y productores de contenidos audiovisuales inmersivos.

Es en este contexto, con el crecimiento exponencial de las cámaras, que se ha generado una demanda y aceptación de la grabación de audio 3D. En las últimas décadas se han producido muchos avances en este medio, como la tecnología HD, el sonido envolvente Dolby Surround y las imágenes 3D, pero sólo algunas como 
la incorporación de sonido y de color han sido revolucionarias. Este incremento de significado que adoptan las imágenes al conjugarse con el sonido es lo que Michel Chión denomina valor añadido:

Por valor añadido designamos el valor expresivo e informativo con el que el sonido enriquece una imagen dada, hasta hacer creer, en la impresión inmediata que de ella se tiene o el recuerdo que de ella se conserva, que esta información o esta expresión se desprende de modo natural de lo que se ve, y está ya contenida en la sola imagen (Chión, 1992, p. 33).

El sonido siempre ha jugado un papel importante en el audiovisual y para Chión, (1992, p. 64) sus funciones principales son:

- Influencia en las percepciones del movimiento y la velocidad.

- Influencia sobre la percepción del tiempo en la imagen.

- Reciprocidad y congruencia con la imagen en movimiento.

- Información o connotación de lugar.

- Relación con la diégesis.

En este contexto, el sonido ha evolucionado no sólo desde la semiótica sonora sino también desde la parte técnica. En este campo, la comunicación también ha modificado sus formatos de presentación al pasar de sistemas monofónicos en los años 30, al estéreo en los 40 y a la llegada de formatos envolventes en los 80 , hasta consolidar el audio envolvente o también llamado "Surround" (Fukada, 1999), por el origen del término en inglés. Este puede ser creado de diferentes maneras. La primera es mediante micrófonos biaurales donde su presentación varía dependiendo del uso; pueden ser a través de audífonos que en vez de reproducir sonido crean grabaciones holofónicas; también se puede desarrollar a través de una cabeza o Dummy Head, cuyos precios oscilan entre los USD\$100 y los USD\$8000. La segunda manera de grabación es mediante una técnica denominada Ambisonic, donde por medio de un micrófono con múltiples diafragmas posicionados en distintas direcciones realizan la grabación; sus precios van desde USD \$300 hasta USD \$3000. El sonido envolvente es algo más que una suma de avances tecnológicos. Es la

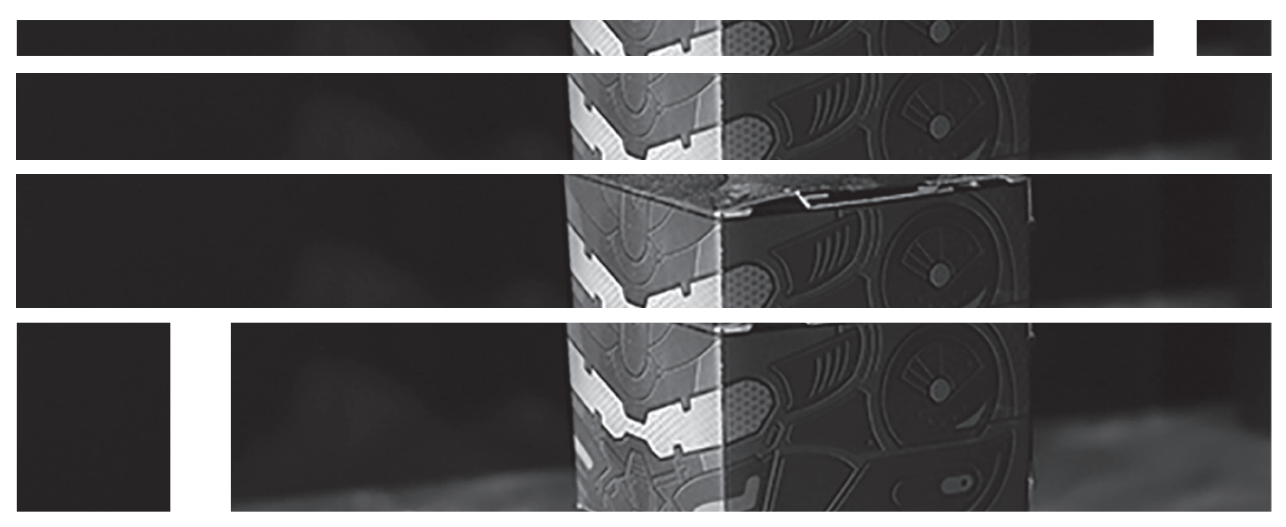


búsqueda de una inquietud que tiene como objetivo recrear, en la medida de lo posible, un entorno sonoro que se aproxime al concepto omniespacial de 360 grados. "En otras palabras, dotar al sonido de un campo de acción con 360 posibles ejes de incidencia, bien con un afán de construcción realista o, sencillamente, en pro de la máxima expresividad” (Pueo \& Sánchez, 2011, p.7).

La democratización de las tecnologías se implementa en los dispositivos móviles; éstos cuentan ahora con una pantalla y un sistema de giroscopio que permite activar la opción de "ver en realidad virtual". Cabe resaltar que para tener una mejor inmersión es necesario usar gafas de realidad virtual o gafas virtuales, entre las que se encuentran Oculus Rift, Google Cardboard o Samsung Gear VR. Siguiendo líneas anteriores, en el último año, plataformas como Youtube, Facebook, Periscope y ahora se suma Twitter, han incorporado la tecnología necesaria para que los usuarios suban y previsualicen vídeos en $360^{\circ}$. En la actualidad se cuenta con plataformas alternas especializadas en realidad virtual para compartir videos y fotos de 360 grados sin problemas.

La tendencia a utilizar realidad virtual, $V R$ y el vídeo $360^{\circ}$ ha interesado a países como Argentina, que desarrolló desde el Ministerio de Turismo, en conjunto con la Unesco, el proyecto Argentina 360 VR: Patrimonio de la Humanidad Intangible UNESCO “Tango"y "Filete Porteño" (2016). También destacamos los proyectos Descubre Dinamarca (Take a virtual tour of Denmark) y Video 360 San Agustín Huila Colombia, creado por la empresa Panoramik.

\footnotetext{
Gracias a los avances tecnológicos en la sociedad de la información y las comunicaciones, los sistemas de comunicación inmersiva han hecho aparición recientemente en la escena social y se han probado con éxito en el mundo del entretenimiento. El objetivo de todos ellos ha sido brindar verosimilitud al estímulo artificial para provocar en el espectador una serie de sensaciones asociadas al dramatismo de la narrativa audiovisual (Pueo \& Sánchez, 2011, p.2).
}

El video es una suma de fotogramas o imágenes que se reproducen sincrónicamente en un segundo; las imágenes al igual que el lenguaje verbal tienen la propiedad de comunicar. Como lo ha estudiado la semiótica, la imagen como los textos tiene unas formas de expresión (significante) y un contenido (significado). Los estudios de semiótica concluyen que para que diversas maneras de expresión como pintura, dibujo o fotografía, sean capaces de transmitir un contenido, tienen que establecerse ciertos consensos socio-culturales que puedan configurar un posible sentido dentro de las convenciones de la percepción de la realidad; sin estos acuerdos no es posible transmitir y dar a entender un mensaje.

Si comenzamos a descubrir una de las características más controversiales de la imagen para la semiótica es su propiedad icónica, es decir, la capacidad de parecerse visualmente al objeto que representa sin serlo, copiando su apariencia 
visual. No obstante, la semiótica trata a la imagen dentro un contexto netamente comunicativo, sin tener en cuenta la forma como el cerebro humano lee las imágenes a través de una cognición encarnada. La semiótica aborda el problema desde las convenciones creadas por las sociedades para poder transmitir información por medio de las imágenes.

Entender por qué el carácter icónico tiene relevancia en el uso de imágenes en la construcción de relatos nos conduce al concepto de mimesis ${ }^{5}$, para comprender que nuestro cerebro ha evolucionado la habilidad de entender, aprender e imitar las acciones de otros y asimilar a las propias. La mimesis hace posible el entendimiento entre varios grupos de individuos y asimismo posibilita la creación de tratos para la comunicación, facilitando la creación de sociedades y culturas. También hace referencia a nuestra capacidad de imitar, lo que requiere una compresión de los actos de los otros y de su asimilación como actos propios; es decir, es un procedimiento donde el cerebro asimila al otro y proyecta su conciencia en él. Se puede hablar de una proyección del "yo" sobre el otro. A este fenómeno usualmente se le conoce como empatía ${ }^{6}$ y es una característica esencial de la conciencia humana que hace diferenciarse radicalmente de los primates, animales con la capacidad de imitar (Donald, 1998).

La empatía es la responsable de la generación de sentimientos relacionados generalmente con las narrativas en tercera persona. Sentimientos como la simpatía, la admiración, la lástima, la pena o el respeto, permiten que nos identifiquemos e involucremos con las experiencias de los otros. Lo podemos identificar en narrativas visuales como el cine, que recurre a la empatía para involucrar emocionalmente al observador así sea de una manera pasiva en los sucesos acontecidos por los protagonistas.

La empatía está directamente relacionada con lo que la neurociencia ha denominado el sistema de neuronas en espejo, responsables de procesos que involucran el aprendizaje y la simulación encarnada; esta última es fundamental para que las narrativas audiovisuales tengan éxito en lo que se conoce como inmersión, es decir, la capacidad de una imagen para involucrar en términos de realidad a su espectador, al punto que el cuerpo reaccione de la misma manera al enfrentarse a experiencias verdaderas o ficcionales.

En los análisis que se han realizado, se ha determinado que el sistema de neuronas en espejo también se activa cuando una persona realiza una acción concreta, por ejemplo, agarrar una taza si ve que alguien más lo hace o soñar o imaginar que lo está haciendo. Esto quiere decir que el cerebro humano tiene la capacidad de simular situaciones, a tal punto que se producen percepciones, emociones y reacciones, como si realmente se estuvieran realizando dichas acciones. Lo anterior permite que las narrativas audiovisuales como el cine y la realidad virtual sean capaces de generar simulaciones encarnadas en los espectadores y consigan involucrarse a nivel 
perceptivo y emocional. La simulación, termino pilar de la realidad virtual, también es entendida como un mecanismo que permite al cerebro asimilar lo que está experimentado (percepciones, imaginaciones y anticipaciones), comparándolo con la memoria de sucesos ya vividos, hábitos y rutinas corporales. Esto le permite a la mente humana saber cómo actuar y qué decisiones tomar frente a lo que está viviendo. Este mecanismo está presente en los sueños, la imaginación, los relatos audiovisuales inmersivos o sencillamente al conocer vivencias de otros individuos y permite al cerebro anticipar decisiones frente a posibles acontecimientos reales.

Para esta instancia, se puede concluir que las narrativas audiovisuales inmersivas y las imágenes miméticas en general tienen el poder de comunicar un contenido o significado en términos semióticos y también son capaces de generar percepciones, emociones y sentimientos a través de lo que podemos denominar una "mente encarnada”. Las imágenes reflejan cómo nuestro cerebro ha evolucionado para interactuar con el mundo y generar los mecanismos que nuestra conciencia usa para prever, anticipar, aprender y entender posibles situaciones. Nuestro cerebro encarnado, en muchas ocasiones, reacciona igual a situaciones reales o hipotéticas, pero debe ser la conciencia la que determine qué es real y qué no lo es, aunque nuestro cuerpo se comporte de la misma forma en ambas situaciones.

Gracias a los avances tecnológicos en la sociedad de la información y las comunicaciones, los sistemas de comunicación inmersiva como se le conoce a la evolución de la comunicación tradicional se diferencian al implementar una comunicación sensorial o comunicación a través de los sentidos y la inmersión, gracias al uso de tecnologías como la holografía, videomapping, realidad virtual, realidad aumentada, 3D Motion graphics.

La publicidad y los videojuegos han implementado el uso de la comunicación inmersiva; así mismo han hecho aparición reciente en la escena social y se han probado con éxito en el mundo del entretenimiento. "El objetivo de todos ellos ha sido brindar verosimilitud al estímulo artificial para provocar en el espectador una serie de sensaciones asociada al dramatismo de la comunicación audiovisual" ( Pueo \& Sánchez, 2011, p.2). Los profesionales de la comunicación han explotado los beneficios del sentido de la vista mediante distintas técnicas en aras de un impacto sensorial elevado; 
algunas de sus propuestas se han implementado tímidamente en el ámbito educativo, especialmente en la etapa de educación superior.

En otras palabras, el nivel de inmersión es la facultad que poseen las narrativas audiovisuales para involucrar emocionalmente al espectador, de modo que las imágenes no son más reales porque copien a la perfección la apariencia de las cosas sino por su habilidad de crear experiencias encarnadas en diversos estados emocionales ${ }^{7}$.

\subsection{Movie in the brain.}

Como se ha mencionado, los relatos audiovisuales tienen poder sobre nosotros porque son producto de varios mecanismos que nuestro cerebro encarnado utiliza para aprender del mundo y de los otros. No obstante, todavía no se ha analizado la forma como la conciencia humana genera relatos que permiten a los individuos realizar tareas específicas con objetivos puntuales, ni tampoco cómo la arquitectura de estos relatos es tan parecida a la forma como se hace el cine o se experimenta un videojuego.

Hay dos términos que son determinantes para entender cómo opera la conciencia humana y su relación con los relatos audiovisuales, El primero es Movie in the brain, acuñado por el científico Antonio Damasio en su estudio sobre reconocimiento de la conciencia del individuo de sí mismo en su constante interacción con el mundo. El otro concepto es el creado por el autor Torbel Grodal y conocido como Flujo PECMA, un análisis sobre cómo el ser humano genera conocimiento a través del cerebro encarnado.

Antonio Damasio describe cómo la conciencia, por medio de un relato vivido, trata todo el tiempo de mantener el conocimiento sobre el individuo en sí. En este proceso la persona no es un narrador externo sino que está implícito en la historia como protagonista, permitiendo que se reconozca en sus acciones e interacciones con el mundo exterior. Para Damasio el cine es una narrativa que se asemeja a la manera como se construye la conciencia en el cerebro encarnado (Damasio, 2000). Se podría entonces mirar el "relato" como un mecanismo que utiliza la conciencia humana para establecer una serie de experiencias bajo un objetivo específico, en una línea de tiempo determinada.Y es gracias a este mecanismo que le encontramos sentido a nuestras acciones en la cotidianidad, como ir a trabajar o a estudiar, hacer mercado, etc. Sin los relatos, el cerebro no tendría claro el fin último de nuestras acciones ni el pasado que las soporta y viviría en un estado de confusión permanente. El grado superior de la conciencia es, por consiguiente, un narrador interno que nos cuenta los relatos de nuestra existencia (Grodal, 2009).

Como lo hemos visto, el relato no es una forma de narrativa verbal, es pre-verbal. Lo que sucede es que el hombre, a lo largo de su evolución cognitiva, ha configurado 
modos de mediación que le dieron nuevas posibilidades y que contribuyeron a mejorar su construcción y su preservación. Grodal establece así una cronología en donde primero estuvo el relato oral, luego el relato escrito, luego el relato teatral, el cinematográfico y el computacional, haciendo hincapié en que los dos últimos son los más cercanos a la experiencia humana en el mundo ${ }^{8}$ (Grodal, 2009).

Grodal va más allá de definir el papel del relato en la conciencia humana y se pregunta sobre el proceso que permite que sea construido en nuestro cerebro encarnado. Para tal fin, Grodal nos presenta el concepto de Flujo PECMA (Percepción, Emoción, Cognición, Motricidad y Acción), proceso donde el cerebro no recibe pasivamente información sino que genera una serie de acciones de orden emocional y motor, basado en los estímulos que provienen de los sentidos. Es un esquema que muestra la estructura del cerebro cuando vive una experiencia en general y la manera como la procesa (Grodal, 2009).

El cerebro recibe información del mundo por medio de los sentidos, trata de organizar los datos suministrados al identificar formas, colores, dimensiones, sonidos, olores, etc. y posteriormente los compara con rasgos ya almacenados en la memoria. Es decir, genera una percepción cuya función es darle algún sentido a esa información y, al pasar por el sistema límbico, produce emociones con tendencias a la acción, ya sea para acercarse o para alejarse de algo. Podemos entender mejor este proceso cuando nos enfrentamos a una película de terror o cuando vemos escenas que nos hacen reír o llorar: nuestro cuerpo reacciona y toma actitudes al enfrentarse a este tipo de narrativas. Las películas en su mayoría son relatos de tipo canónico y lineal (tienen un inicio, un nudo y un desenlace, en una línea de tiempo cronológica definida); esto se debe a que la conciencia humana y el sentido de realidad se experimentan de esta forma y, a su vez, cuando el Flujo PECMA termina se ha cumplido una meta específica.

El término realidad virtual ha tomado gran importancia en los últimos años de acuerdo con Manetta y Blade (2015): "La realidad virtual es un sistema de computación usado para crear un mundo artificial en el cual el usuario tiene la impresión de estar y la habilidad de navegar y manipular objetos en él” (p. 65). En 1986, Jaron Lanier, acuñó el término Realidad Virtual (RV):

La RV es una tecnología que permite la creación de espacios tridimensionales por medio de un ordenador; es decir, permite la simulación de la realidad, con la gran ventaja de que podemos introducir en el ambiente virtual los elementos y los eventos que consideremos útiles, según el objetivo que nos propongamos. Para poder producir una experiencia virtual necesitamos un ordenador, un programa informático con el contenido del mundo virtual, un dispositivo para visualizar el mundo virtual (Lanier, 1988, p.4). 
Se puede concluir que las imágenes en movimiento como las producidas por el cine, el vídeo, la televisión, los vídeojuegos y la realidad virtual son un reflejo de la forma como funciona nuestra conciencia al darle sentido a nuestras acciones a través del establecimiento de objetivos y la narración de una voz interior que permite identificarnos a nosotros mismos en interacciones cotidianas con lo que nos rodea.

\section{Conclusiones}

Nuestro sistema perceptivo ha cambiado debido a la mediación de las imágenes: Teniendo en cuenta que nuestra experiencia cotidiana está entramada por dispositivos tecnológicos que todo el tiempo nos bombardean con relatos, estamos cada día en mayor contacto con las imágenes del mundo. Cada día se crean nuevos proyectos de realidad virtual totalmente inmersiva añadiendo nuevos puntos a estas recreaciones como lo son vibraciones, vapor, olores, micro cargas para lograr un realismo que a futuro superará a la realidad.

Conceptos como cognición, simulación encarnada, empatía e inmersión, nos amplían el panorama de la percepción de las imágenes, permitiendo comprenderla no sólo al nivel de transmisoras de un mensaje, sino como una experiencia que actúan a nivel visual, sonoro y muscular; es decir: transmiten emociones que afectan a todo el cuerpo y hacen que éste reaccione frente a procesos ficcionales, sin que pierda la conciencia de la irrealidad en que se encuentra.

En el caso del estudio de las narrativas audiovisuales, estos conceptos mencionados anteriormente permiten conocer mejor la forma de trabajar de nuestro cerebro. Actualmente las narrativas visuales ocupan un lugar importante en nuestra sociedad, porque son un reflejo de la forma como interactúa el cerebro humano con su entorno y su capacidad de asimilar a los otros como una proyección de sí mismo, lo que resulta en el reconocimiento e intercambio de emociones y cogniciones con los demás.

Las tecnologías actuales de las imágenes miméticas son exitosas en su uso social, cultural y científico, porque reflejan cómo funciona nuestra mente cuando crea realidades; además nos muestran la forma en la que opera nuestra conciencia para generar relatos a partir de nuestras percepciones, emociones, sentimientos y cogniciones. Lo anterior nos permite cumplir con objetivos y tareas concretas, a la vez que creamos mecanismos para entender quiénes somos y cómo nos diferenciamos e integramos a los otros en el mundo.

Aunque es una tecnología nueva que requiere diferentes reconfiguraciones en el aumento de calidad de presentación visto en términos de resolución y codificación, ya está generando nuevas experimentaciones, usos y narrativas. Como lo plantean Castejón y Méndez (2012), el futuro del patrimonio cultural y el turismo y las redes sociales han modificado el eje articulador de presentación y comunicación

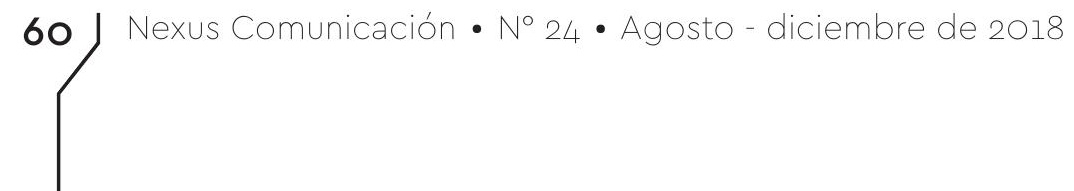


del patrimonio cultural, puesto que el usuario cada vez es más un prosumidor que multiplica estas experiencias en redes sociales como YouTube y Facebook. De hecho, así lo piensan IRALTA FILMS , quienes aseguran que en un futuro cercano el desarrollo de esta tecnología permitirá cambiar la concepción de realismo así como la exploración de nuevos mundos sólo descritos en la ciencia ficción. Siguiendo líneas anteriores, Ruiz (2013) afirma: “Aquí el individuo no queda inmerso en un mundo virtual, sino que mejora o aumenta el espacio que le rodea con elementos generados por ordenador o smartphone que complementan la realidad" (p.33). Podríamos dejar el debate abierto y preguntarnos: ¿Cómo esta condición de la sociedad actual repercute en la forma como interactuamos entre nosotros? ¿Cómo los conceptos de realidad y ficción se mezclan cada vez más?

Cerrando las ideas, la industria audiovisual, tecnológica y comunicacional ya han iniciado planes de acción enfocados al desarrollo y posicionamiento de la realidad virtual. Es el momento que mediante políticas gubernamentales se aplique a temáticas relacionadas con la educación la cultura y la convivencia.

¿Algún día nuestra conciencia ya no será capaz de dictaminar la diferencia entre la realidad y la ficción?
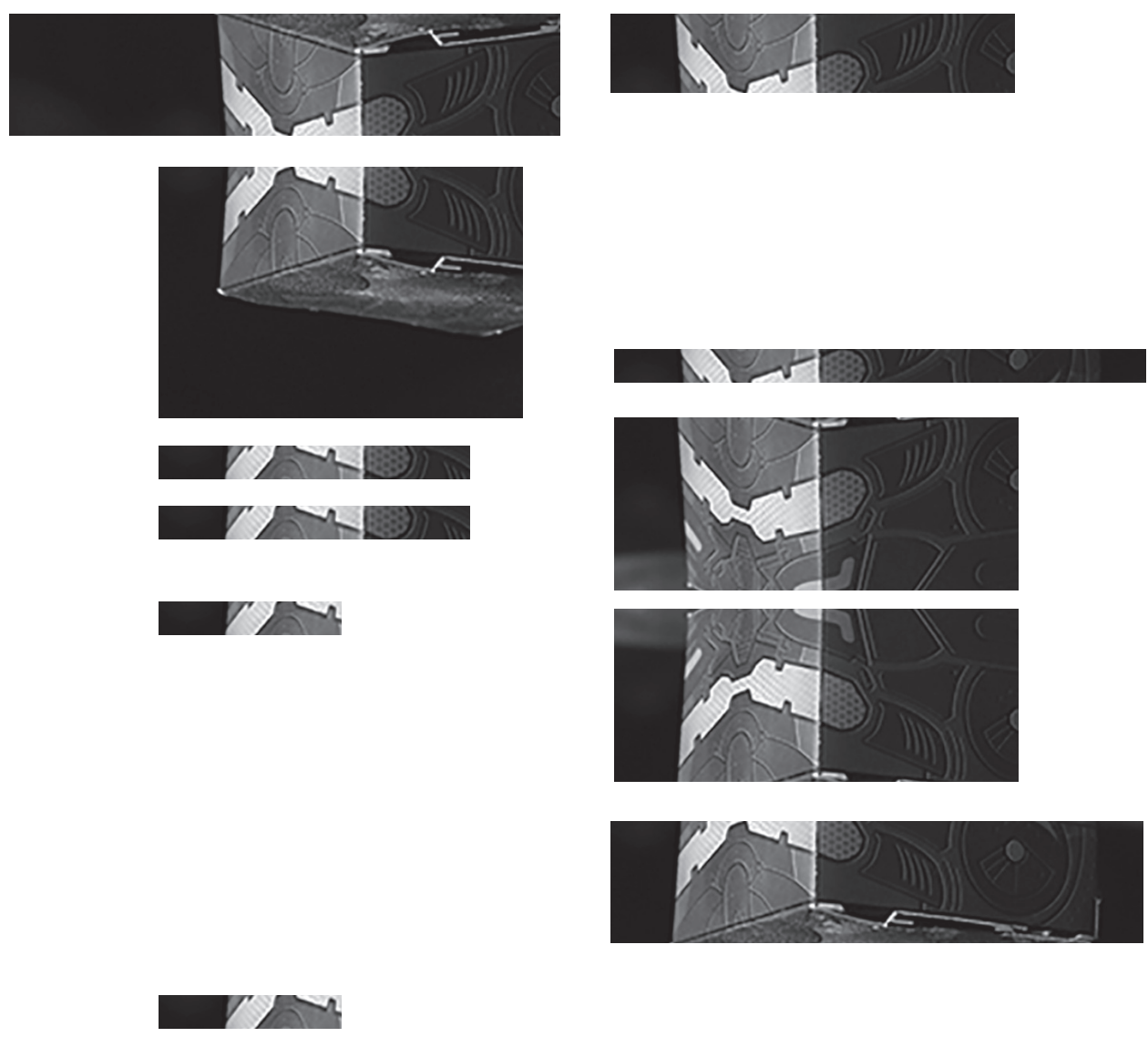


\section{Notas}

${ }^{1}$ Investigación matriz del texto: La comunicación inmersiva mediada por la realidad virtual a través de video $360^{\circ}$ en la comunicación del patrimonio cultural del centro de Bogotá. Fundación Universitaria Libertadores.

2 Docente cátedra de la Fundación Universitaria Los Libertadores y co-investigador del proyecto La comunicación inmersiva mediada por la realidad virtual a través de video $360^{\circ}$ en la comunicación del patrimonio cultural del centro de Bogotá. Aspirante a Magister en Estética e Historia del arte de la Universidad Jorge Tadeo Lozano, Especialista en Fotografía de la Universidad Nacional de Colombia, Maestro en Artes Plásticas de la Universidad Nacional de Colombia.

${ }^{3}$ Docente investigador tiempo completo de la Fundación Universitaria Los Libertadores, investigador principal del proyecto: La comunicación inmersiva mediada por la realidad virtual a través de video $360^{\circ}$ en la comunicación del patrimonio cultural del centro de Bogotá. Ingeniero de sonido de la Universidad San Buenaventura Bogotá, Magister de la Universidad Politécnica de Valencia en postproducción Digital.

${ }^{4}$ Como lo ha sabido expresar en su estudio sobre arte y evolución cognitiva, el autor Merlin Donald señala que la producción de imágenes está sometida a los desarrollos tecnológicos de las sociedades que las crean, lo cual quiere decir que la tecnología que se utilizaba para crear imágenes en el Renacimiento no va a ser la misma que la usada en la actualidad. En nuestro tiempo, la producción de imágenes está dominada por los dispositivos electrónicos como cámaras fotográficas, de vídeo, celulares, ordenadores, etc.

5 La mimesis no es un concepto que aborde la imagen desde su propiedad icónica, sino que trata de señalar que los seres humanos que producen estas imágenes saben que está imitando, no tanto la apariencia física de las cosas, sino a los otros en sus modos de ver la realidad.

6 "Empathy is the phenomenal experience of mirroring ourselves into others. It can be explained in terms of simulations of actions, sensations, and emotions, which constitute a shared manifold for intersubjectivity. Simulation, in turn, can be sustained at the subpersonal level by a series of neural mirror matching systems" (Tikka 2006, pag. 232).

7 Si se hiciera una comparación entre el nivel de inmersión causada por juegos de realidad virtual y películas, nos daríamos cuenta que a pesar de que los juegos incluyan la primera persona y la sensación de estar ahí, muchas veces no generan el mismo nivel de inmersión que un film, porque no consiguen que el espectador se involucre emocionalmente.

8 Los relatos verbales, escritos y audiovisuales, han desarrollado la narrativa en tercera persona, a diferencia de los juegos de vídeo o por ordenador, que desarrollan la narración en primera persona. Un ejemplo exitoso de esto es el videojuego Mirror Edge, sacado al mercado en el año 2008 y que trata de ofrecer al usuario una interfaz que imita - por medio de la animación de la cámara- cómo nos vemos a nosotros mismos en una situación real. 


\section{Referencias}

Adams Becker, S., Johnson, L., Gago, D., Garcia, D., \& Martín, S. (2013). Perspectivas Tecnológicas> Educación Superior en América Latina 2013-2018. Texas: The New Media Consortium.

Aukstakalnis, Steve; blatner, David; Roth, Stephen F. El espejismo de silicio: arte y ciencia de la realidad virtual. 1993.

Caro, J. L., Luque-Gil, A. M., \& Zayas-Fernández, B. (2014). Aplicaciones tecnológicas para la promoción de los recursos turísticos culturales.

Castejón, R.; Méndez, E. Introducción a la economía para turismo: Editorial Prentice-Hall; 2012. ISBN 978-84-8322-522-6.

Chión, M. (1992). Los oficios del cine. Madrid, Cátedra.

Cuadrado, T. (2005). Características de la comunicación audiovisual.

Damasio, A. (2000). Sentir lo que sucede. Santiago de Chile: Editorial Andrés Bello.

Domínguez, E. (2015). Periodismo inmersivo o cómo la realidad virtual y el videojuego influyen en la interfaz e interactividad del relato de actualidad. El profesional de la información, 24(4).

Donald, M. (1998). Mimesis and the executive suite: Missing links in language evolution," in J. R. Hurford, M. Studdert-Kennedy and C. Knight (eds.), .

Grodal, T. (2009). Embodied visions: Evolution, emotion, culture, and film. Oxford University Press.

Lanier, J. (1988). A Vintage Virtual Reality Interview, 1988. Interview by Adam Heilbrun of Jaron Lanier, published.

Levis, D. (1997). ¿Qué es la realidad virtual?. línea], disponible en: http://www. diegolevis. com. ar/ secciones/Articulos/Que_es_RV.pdf, recuperado, 21.

López Hidalgo, A. (2016). El periodismo que contará el futuro.

Manetta, Carol; Blade, Richard A. (2015) Glossary of virtual reality terminology. International Journal of Virtual.

Johnson, L., Adams, S., Gago, D., García, E., \& Martín, S. (2013). NMC Perspectivas tecnológicas: educación superior en América Latina 2013-2018. Un análisis regional del informe Horizon del NMC.Austin, Texas: The New Media Consortium.

Kipper, G., \& Rampolla, J. (2012). Augmented Reality: an emerging technologies guide to AR. Elsevier.

González Pérez, A. (2011). Evaluación del impacto de las políticas educativas TIC en las prácticas de los centros escolares.

Pueo, B., \& Sánchez-Cid, M. (2011). El sonido envolvente en entornos audiovisuales inmersivos. Propuestas en el ámbito educativo. Revista ICONO14 Revista científica de Comunicación y Tecnologías emergentes, 9 (2), 167-184

Rheingold, H. (1994). Realidad virtual: los mundos artificiales generados por odenador que modiicarán nuestras vidas. Barcelona: Gedisa.

Ruiz Torres, D. R. (2013). El papel de la realidad aumentada en el ámbito artístico-cultural: la virtualidad al servicio de la exhibición y la difusión (Doctoral dissertation, Universidad de Granada).

Recibido: 11 de abril de 2018 / Aprobado: 1 de diciembre de 2018 